\title{
Cost-Effective Ophthalmic Surgical Wetlab Using the Porcine Orbit with a Simple Dissection Protocol
}

\section{Edak Ezeanosike ${ }^{1 *}$, June Chizoba Azu-Okeke1, Eberechukwu Ogbeanu Achigbu², Chinyelu Nkemdilim Ezisi', Dilichukwu Isioma Aniemeka1, Chimdia Ezioma Ogbonnaya1, Chimdi M. Chuka-Okosa ${ }^{3}$}

\author{
${ }^{1}$ Department of Ophthalmology, Federal Teaching Hospital, Abakaliki, Ebonyi State, Nigeria \\ ${ }^{2}$ Department of Ophthalmology, Federal Medical Centre, Owerri, Imo State, Nigeria \\ ${ }^{3}$ Department of Ophthalmology, University of Nigeria Teaching Hospital, Ituku-Ozalla, Enugu, Nigeria \\ Email: *edakspeaksout@gmail.com
}

How to cite this paper: Ezeanosike, E., Azu-Okeke, J.C., Achigbu, E.O., Ezisi, C.N., Aniemeka, D.I., Ogbonnaya, C.E. and Chuka-Okosa, C.M. (2019) Cost-Effective Ophthalmic Surgical Wetlab Using the Porcine Orbit with a Simple Dissection Protocol. Open Journal of Ophthalmology, 9, 183-193.

https://doi.org/10.4236/ojoph.2019.94020

Received: June 10, 2019

Accepted: November 3, 2019

Published: November 6, 2019

Copyright $\odot 2019$ by author(s) and Scientific Research Publishing Inc. This work is licensed under the Creative Commons Attribution International License (CC BY 4.0).

http://creativecommons.org/licenses/by/4.0/

\begin{abstract}
Objective: To describe the dissection protocol for the pig head to obtain the orbital tissue, as well as a simple setup for ophthalmic surgical wetlabs. Methods and Analysis. A descriptive study. The pig head dissection was performed at the abattoir for convenience. The orbital tissue thus obtained was used to set up the wetlab workstation. Results. A cost-effective, low technology, affordable set-up for ophthalmic surgical wetlab protocol was developed. High resolution photographs of the procedure were taken and were presented for ease of description. The dissection protocol was test-run at an ophthalmic surgical training workshop. Conclusions. The porcine orbit and the wetlab setup were available and affordable. The dissection in the abattoir is easy and reproducible. The orbit was used instead of the enucleated globe and this ensures stability throughout surgical practice sessions.
\end{abstract}

\section{Keywords}

Wet Lab, Ophthalmic Surgical Training, Pig Eye, Porcine Orbit Dissection

\section{Introduction}

Ophthalmic surgery is a very delicate procedure [1] with safety margin for error as small as 4 microns for phacoemulsification [2]. Manual dexterity, tissue handling and surgical precision are key to achieving desired outcomes [3]. Poor surgical skills can result in devastating outcomes [4] including irreversible vision loss [5] [6] [7], or outright phthisis of the globe [8]. Ophthalmic surgical training 
has a steep learning curve [9] with large numbers required for increasing stepwise competence [9]. Wetlabs and simulators have been shown to improve competence and increase safety margin in trainee surgery [10] [11] [12]. However, these are not perfect simulators of a live ophthalmic surgical environment [13].

Several animal eyes have been used over the years for surgical practice by amateur surgeons [14] [15] who graduate to human eyes when a safe level of competence has been achieved. Some popular for intraocular surgery are the enucleated pig, sheep or the goat eyes [14] [15] [16] [17]. A common challenge with these enucleated eyes is keeping the globe stable for the surgical practice procedure. Several gadgets have been described [16] and devices for stabilisation of the globe designed which are available in the market for surgical wetlab use. Suspension cups with either frictional fixation (velcro lining), transverse fixation needle through the globe or vertical fixation pins suspended with rubber bands have been tried [18]. Pig eyes along with the eyelid and orbital tissues fixated on a Styrofoam head model and fixated with a pin, have also been reported [19]. Uhlig and Gerding described a metal cylinder with a polymethylmethacrylate (PMMA) base as the eye support and a metal ring to lock it in place for vitreoretinal surgical practice [20]. Empty plastic containers stuffed with cotton wool and mounted on a thermocol to hold goat eyes for surgical practice have also been described [16]. The additional cost of these devices, the unnatural surgical environment created and the technicalities involved may be drawbacks to sustainable use of these devices, especially in resource-constrained environments.

We describe here a novel and easily reproducible setup for ophthalmic surgical wetlabs using the porcine orbit which offers both surgical tissue simulating the natural surgical environment, as well as stability during surgical practice.

\section{Aims}

To describe the dissection protocol for the pig head to obtain the orbit as well as a simple setup for ophthalmic surgical Wetlabs.

\section{Settings and Design}

We describe a 2-staged procedure. The first is the dissection of the pig head which was carried out by a butcher under guidance at the abbatoir to obtain a block of orbital tissue for the wetlab. At the wetlab, we describe a simple, affordable setup for stable tissue dissection and surgical practice. This study was carried out in the Department of Ophthalmology, Alex Ekwueme Federal University Teaching Hospital, Abakaliki, in April 2018 and was test-run at the First Abakaliki International Oculoplasty Workshop on $22^{\text {nd }}$ May, 2018, where participants performed hands on evisceration with implant placement using this pig orbit model as wetlab tissue. The process has since been modified to improve efficiency.

\section{Materials and Methods}

STEPS IN THE PREPARATION OF THE PORCINE ORBIT FOR THE WETLAB 
A relationship was established with a nearby abattoir for the procurement of the pig head. A staff of the eye unit was assigned the task of obtaining fresh tissue from the abattoir after both he and the butcher have been adequately trained on the proper dissection steps and the dimensions. Fresh pig head was severed as soon as the pig was slaughtered. The freshly-harvested head was washed under running water and laid out on the slaughter table for immediate dissection (Figure 1).

The tongue along with the mandible (Figure 2, right) was disconnected from the rest of the head (Figure 2, left) at the temporomandibular joint and discarded.

The snout was then amputated $2 \mathrm{~cm}$ anterior to the anterior canthus using a power saw or a matchet and a mallet in one decisive cut (Figure 3).

The cranium was then split in the midline, each half bearing an ear and orbit. The intervening brain was exposed (Figure 4).

The residual tissue was then fashioned into a rectangular block using similar power saw or matchet cuts, $2 \mathrm{~cm}$ away from the inferior orbital rim and lateral (posterior) canthus (Figure 5). This procedure was repeated to obtain the second orbital tissue from the contralateral side.

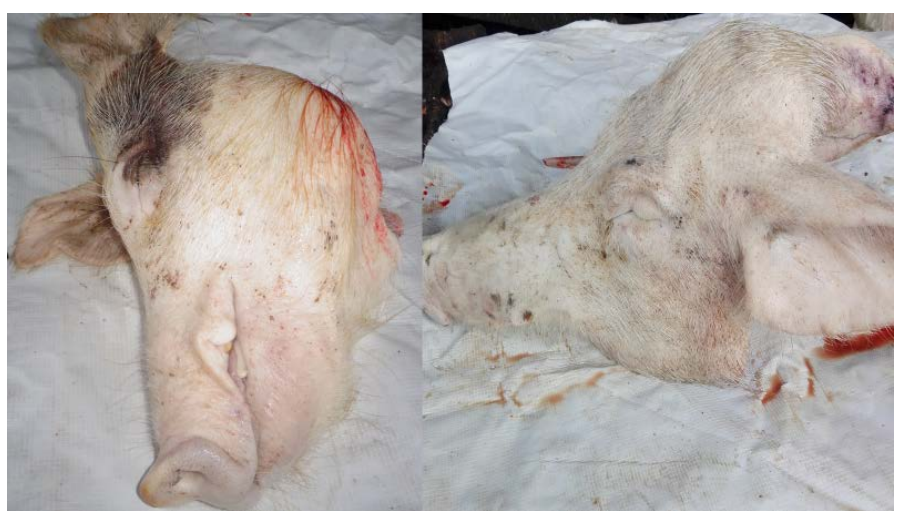

Figure 1. Fresh pig head laid out on the slaughter table.

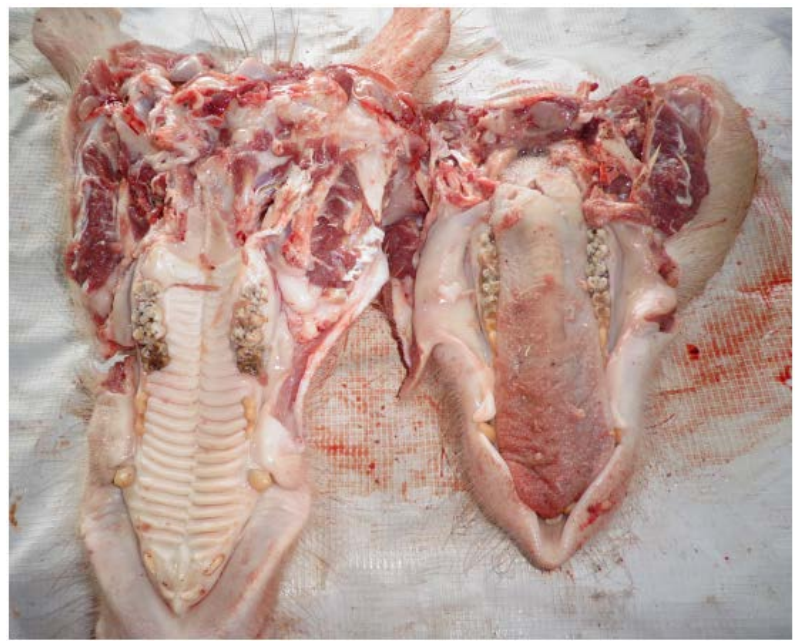

Figure 2. Dissection at the tempero-mandibular joint separating the cranium and maxilla (right) from the tongue and mandible (left). 


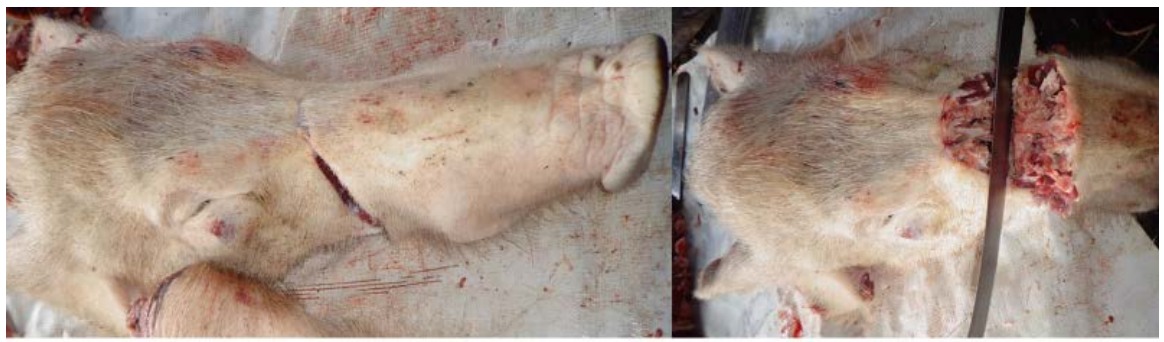

Figure 3. Amputated Snout

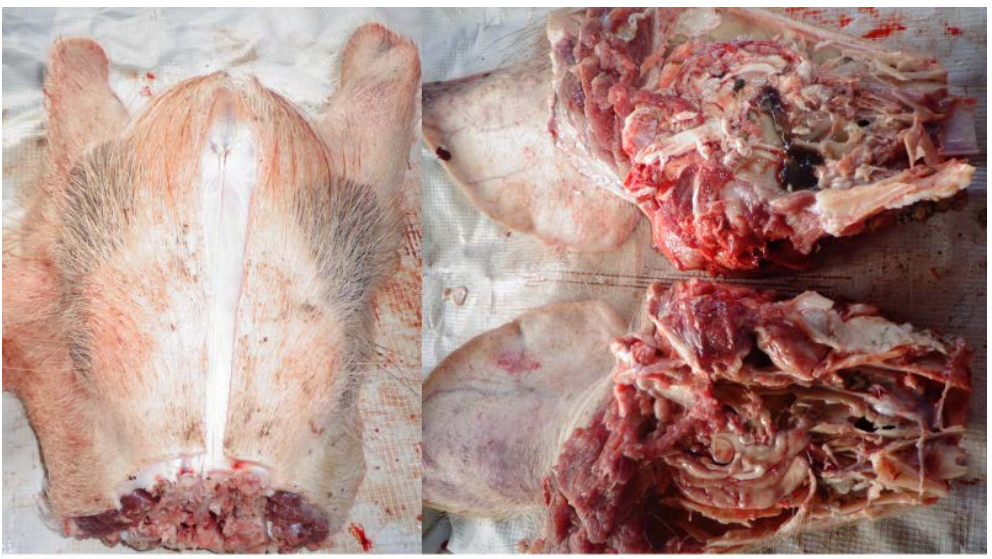

Figure 4. Midline cut through the cranium (left). Exposure of the brain intervening between the orbits (right)

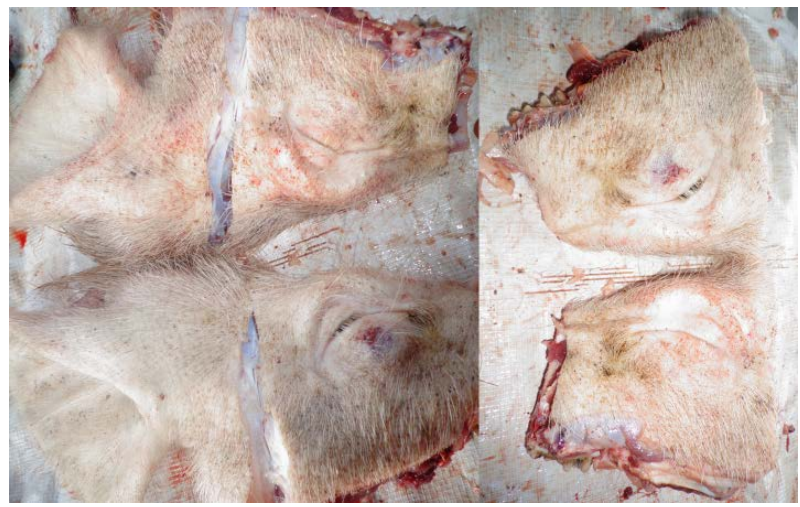

Figure 5. Orbit dissection completed.

\section{Results}

The orbital tissue thus obtained was transported in ice to the wetlab for dissection (Figure 6).

A Formica-topped, or tarpaulin-draped, high wooden stool can be used for the dissection. The work top edges must be wood (not Formica) to allow penetration of the thumbtacks (Figure 7).

The tissue was placed at the centre of the work surface and draped with clingfilm, with the pig's eye open, lashes secured as for routine intraocular surgery and its edges tucked at the sides (Figure 8 left). A fabric surgical drape was then laid over the clingfilm, stretched snugly over the edges of the worksurface 


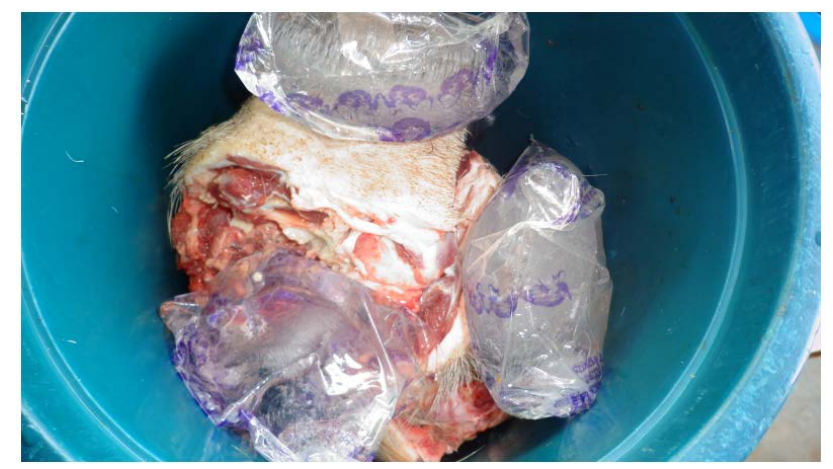

Figure 6. Fresh orbital tissues transported in ice.

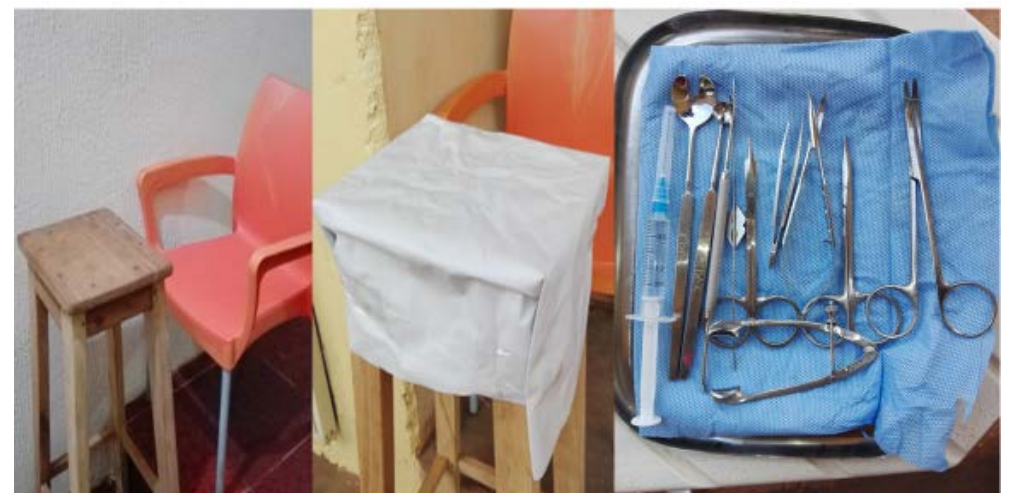

Figure 7. Simple set up for the wetlab Chair Stool covered with tarpaulin and tray of surgical instruments

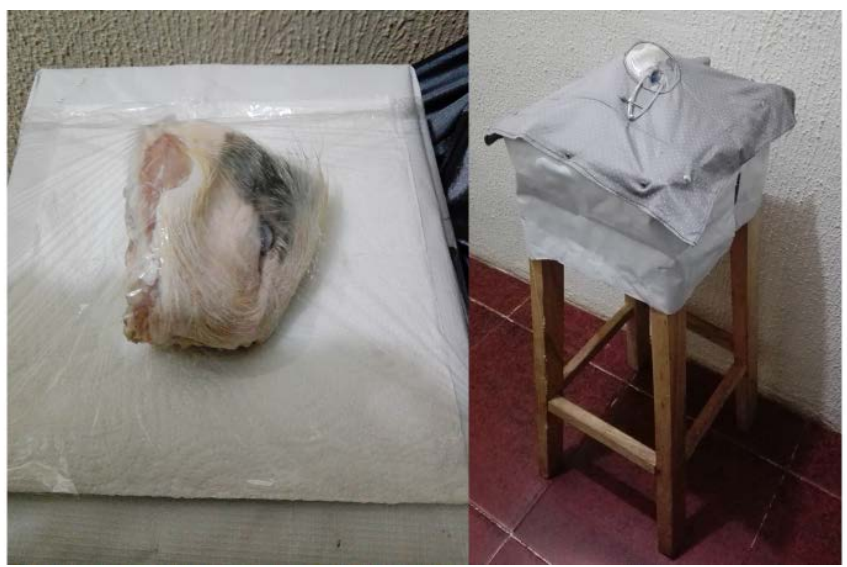

Figure 8. Clingfilm draping off the lashes (left) and surgical drape secured in place with thumb tacks (right).

and secured with thumbtacks keeping the tissue stable for the procedure (Figure 8 right).

The cling film was incised as routine for intraocular surgery and a speculum placed appropriately to drape off the lashes from the surgical field. The nictitating membrane may be tagged using 4.0 silk and secured to the edge of the table with thumbtacks or artery forceps (Figure 9).

Intra or extraocular surgery could then proceed as routine. Draping could also 


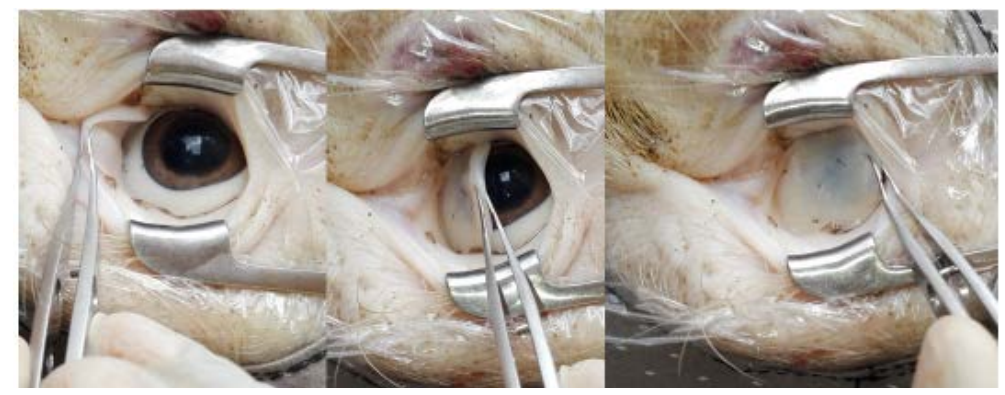

Figure 9. Lids parted with speculum and Nictitating membrane demonstrated

be modified as appropriate to allow for eyelid or orbital surgical practice.

This process was test-run at the First Abakaliki International Oculoplasty Workshop on $22^{\text {nd }}$ May, 2018, where participants performed hands-on evisceration with implant placement using this pig orbit model as wetlab tissue. The process has since been modified to improve efficiency.

\section{Discussion}

The pig is an ideal model for human experimentation as well as surgical training because of its phylogenetic proximity to humans [21] [22], its large size compared to other research animals like rats and guinea-pigs [21], and its availability and affordability compared to monkeys [22]. It has significant anatomical and physiological similarities to humans [21] [23] [24]. Suner and colleagues described the use of the porcine orbit in training emergency physicians in lateral canthotomy to relieve raised intra-orbital pressure in emergent situations [25]. Aurich and co-workers described porcine cranial dissection for the training of Neurosurgeons [26]. Stembirek et al. recommend its use for trial of alloplastic materials that can be used in orbital bony reconstructions [21]. Enucleated pig eyes have been used as practice tools for cataract surgical training as well as other intraocular surgeries like trabeculectomy [14] [27]. The challenge in these procedures has been to stabilise the eye for the delicate procedures. Various devices have been developed to hold the enucleated eye in place for trainee surgery [28] [29] [30]. The need for these devices arose from the challenge of stability of the enucleated animal globe during wetlabs. These devices are not perfect simulators of the live surgical environment. Some also may create significant vitreous pressure while securing the globe, creating additional challenge during surgery. This piece is not a treatise in fine details of porcine gross anatomy, but a descriptive of the applied anatomy of the porcine orbit in comparison to the human orbit, to describe the possible value of porcine orbital dissection in ophthalmic surgical training.

Some of the advantages of this model are its ready availability, affordability and ease of set up, even in resource-constrained environments. Also, phylogenetic similarity of the pig to humans makes it an ideal training model for ophthalmic surgery. Several studies describe the use of animal globes for surgical training. This automatically creates the requirement for a stabilising device. Orbital dissection as described here offers tissue stability obviating the need for a stabilising 
device. The presence of the globe in the orbit precludes the posterior vitreous pressure created by stabilising devices. The simplicity of the set-up described makes it a ready-to-use system that can be replicated in multiples, even in resource-constrained settings.

\subsection{Basic Anatomical Similarities and Differences between the Pig and Human Orbital/Ocular Tissues \\ EYELID ANATOMY}

The pig possesses an upper and lower lid both bearing lashes, similar in length, thickness and distribution to that of humans. There is also a 'third eyelid' (palpebra tertia) arising near the medial canthus which is a semilunar fold of conjunctiva with a leading edge of cartilage arising deep to the medial canthus [6]. It's location is similar to the caruncle and semilunar fold in humans [31] (Figure 9). This palpebra tertia is also known as the nictitating membrane and is present in several other animals like the dog, cat, horse [32] [33] [34] [35]. The nictitating membrane is the analogue of the caruncle in humans and is believed to exude pheromones and serve for photoprotection [36]. The lid margins contain a tarsal plate with similar dimensions and disposition to humans. They are covered with skin anteriorly and conjunctiva posteriorly and would thus be ideal for training in eyelid repair and reconstruction. The conjunctiva is however thicker and whitish (Figure 9). Trainees would therefore need mental readjustment in human surgeries like trabeculectomy where the conjunctiva is definitely more delicate than the pig's.

\subsection{Extraocular Muscles and Soft Tissue Anatomy}

The porcine intraocular anatomy and its comparison to the human ocular structures has been previously elucidated and is beyond the scope of this discussion [37]. Kivell et al. have described the comparative anatomy of the porcine orbit tissues with that of humans, describing significant similarity between the two species in terms of number and location of the extraocular muscles [23]. Both species are strikingly similar in number and location of the extraocular muscles. The key difference they demonstrated was the presence of the retractor bulbi muscle that entirely surrounds the optic nerve perhaps similar to the sheath of the muscle cone in humans [23]. This would be an important consideration in the practice of enucleation surgery.

\subsection{The Bony Orbit}

The porcine bony orbit is shallow and oriented laterally compared to that of humans [21]. While the paranasal sinuses intervene between both orbits in humans, the brain of the pig lies between its orbits. This offers a wide safety margin in the abattoir dissection as inadvertent orbital wall fractures are unlikely to occur. The medial wall is shorter than the lateral in pigs. The bony calvarium attached to the superior orbital wall is far thicker than the residue of the maxilla 
on the inferior orbital wall in our dissection specimen. The trainee may therefore require a small wedge beneath the inferior rim to provide a fairly flat operating surface to simulate the normal environment.

Limitations of the study: Religious constraints in some individuals may preclude handling of tissues from a pig

\section{Conclusions and Recommendations}

The advantage of this technique is that the globe is stable within the orbit and thus simulates natural surgical environment. Also, the set-up is affordable, cost-effective and achievable even in a resource-constrained training environment.

The porcine orbital dissection can be used to teach several ophthalmic surgical procedures including eyelid repair/reconstruction, strabismus surgery, penetrating keratoplasty, corneoscleral repair, trabeculectomy, cataract surgery, vitrectomy, intravitreal injections, evisceration, enucleation, exenteration, trans periorbita tumor delivery. Perhaps many more procedures can be performed on the pig eyes as practice models.

We recommend porcine orbital dissection for all first-year Ophthalmology residents. This may require an understanding of the differences between the human and porcine orbital anatomy as enunciated above for clarity of the applied anatomy. Repeated practices under supervision would lead to improved tissue handling skills as the training progresses. The porcine orbit can also be used for clinical evaluation of acquired surgical skills, following which the trainee may proceed to human dissections. Direct dissection in the orbit would simulate more natural environs and prevent the positive vitreous pressure that may be created by the stabilizing devices.

Key Messages: The porcine orbital dissection as described here can be used to teach several ophthalmic surgical procedures, is affordable, cost-effective and achievable even in a resource-constrained training environment and is recommended for early training of residents in Ophthalmology. Porcine tissue as dissected can also be used for examination purposes to assess candidate performance at selected ophthalmic surgical skills

\section{Acknowledgements}

Many thanks to my Mentor, Dr. Milind Naik for his commitment, guidance and continued support in the practice of Ophthalmic Plastic Surgery.

\section{Conflicts of Interest}

The authors declare no conflicts of interest regarding the publication of this paper.

\section{References}

[1] Nuzzi, R. and Brusasco, L. (2018) State of the Art of Robotic Surgery Related to Vision: Brain and Eye Applications of Newly Available Devices. Eye Brain, 10, 13-24. 
https://doi.org/10.2147/EB.S148644

[2] Ho, J. and Claoue, C. (2013) Cataract Skills: How Do We Judge Competency? Journal of the Royal Society of Medicine, 106, 2-4.

https://doi.org/10.1177/0141076813476412

[3] Jardine, D., Hoagland, B., Perez, A. and Gessler, E. (2015) Evaluation of Surgical Dexterity during the Interview Day: Another Factor for Consideration. Journal of Graduate Medical Education, 7, 234-237. https://doi.org/10.4300/JGME-D-14-00546.1

[4] Agha, R.A., Fowler, A.J. and Sevdalis, N. (2015) The Role of Non-Technical Skills in Surgery. Annals of Medicine and Surgery, 4, 422-427. https://doi.org/10.1016/j.amsu.2015.10.006

[5] Dandona, L. (2001) Cataract Surgery in Very Elderly Patients. Outcome of Cataract Surgery Is Poor in Developing Countries. British Medical Journal, 323, 455.

[6] Dandona, L., Dandona, R., Naduvilath, T.J., McCarty, C.A., Mandal, P., Srinivas, M., et al. (1999) Population-Based Assessment of the Outcome of Cataract Surgery in an Urban Population in Southern India. American Journal of Ophthalmology, 127, 650-658. https://doi.org/10.1016/S0002-9394(99)00044-6

[7] Rabiu, M.M., Kyari, F., Ezelum, C., Elhassan, E., Sanda, S., Murthy, G.V., et al. (2012) Review of the Publications of the Nigeria National Blindness Survey: Methodology, Prevalence, Causes of Blindness and Visual Impairment and Outcome of Cataract Surgery. Annals of African Medicine, 11, 125-130. https://doi.org/10.4103/1596-3519.96859

[8] Boniuk, V. and Boniuk, M. (1970) The Incidence of Phthisis Bulbas a Complication of Cataract Surgery in the Congenital Rubella Syndrome. Transactions: American Academy of Ophthalmology and Otolaryngology, 74, 360-368.

[9] Gupta, S., Haripriya, A., Vardhan, S.A., Ravilla, T. and Ravindran, R.D. (2018) Residents' Learning Curve for Manual Small-Incision Cataract Surgery at Aravind Eye Hospital, India. Ophthalmology, 125, 1692-1699. https://doi.org/10.1016/j.ophtha.2018.04.033

[10] Belyea, D.A., Brown, S.E. and Rajjoub, L.Z. (2011) Influence of Surgery Simulator Training on Ophthalmology Resident Phacoemulsification Performance. Journal of Cataract \& Refractive Surgery, 37, 1756-1761. https://doi.org/10.1016/j.jcrs.2011.04.032

[11] Pokroy, R., Du, E., Alzaga, A., Khodadadeh, S., Steen, D., Bachynski, B., et al. (2013) Impact of Simulator Training on Resident Cataract Surgery. Graefe's Archive for Clinical and Experimental Ophthalmology, 251, 777-781.

https://doi.org/10.1007/s00417-012-2160-z

[12] Solverson, D.J., Mazzoli, R.A., Raymond, W.R., Nelson, M.L., Hansen, E.A., Torres, M.F., et al. (2009) Virtual Reality Simulation in Acquiring and Differentiating Basic Ophthalmic Microsurgical Skills. Simulation in Healthcare, 4, 98-103. https://doi.org/10.1097/SIH.0b013e318195419e

[13] Doyle, L., Gauthier, N., Ramanathan, S. and Okamura, A. (2008) A Simulator to Explore the Role of Haptic Feedback in Cataract Surgery Training. Studies in Health Technology and Informatics, 132, 106-111.

[14] Lee, G.A., Chiang, M.Y. and Shah, P. (2006) Pig Eye Trabeculectomy-A Wet-Lab Teaching Model. Eye, 20, 32-37. https://doi.org/10.1038/sj.eye.6701784

[15] Bhartiya, P., Manjunatha, N.P. and Sharma, N. (2011) Goat Eye with Human Nucleus for Phacoemulsification Training. Journal of Cataract \& Refractive Surgery, 37, 
7-8.

[16] Sengupta, S., Dhanapal, P., Nath, M., Haripriya, A. and Venkatesh, R. (2015) Goat's Eye Integrated with a Human Cataractous Lens: A Training Model for Phacoemulsification. Indian Journal of Ophthalmology, 63, 275-277.

https://doi.org/10.4103/0301-4738.156937

[17] Mohammadi, S.F., Mazouri, A., Jabbarvand, M., Rahman, A.N. and Mohammadi, A. (2011) Sheep Practice Eye for Ophthalmic Surgery Training in Skills Laboratory. Journal of Cataract \& Refractive Surgery, 37, 987-991. https://doi.org/10.1016/j.jcrs.2011.03.030

[18] Leuschke, R., Bhandari, A., Sires, B. and Hannaford, B. (2007) Low Cost Eye Surgery Simulator with Skill Assessment Component. Studies in Health Technology and Informatics, 125, 286-291.

[19] Hiroyuki, N., Yu, W., Yumiko, M., Yuko, O., Ari, S., Takayuki, H., et al. (2017) Wet Laboratory Training Using Porcine Eyes with Eyelids. Canadian Journal of Ophthalmology, 52, 398-402.

[20] Uhlig, C.E. and Gerding, H. (2004) Illuminated Artificial Orbit for the Training of Vitreoretinal Surgery in Vitro. Eye, 18, 183-187. https://doi.org/10.1038/sj.eye.6700596

[21] Stembirek, J., Kyllar, M., Putnova, I., Stehlik, L. and Buchtova, M. (2012) The Pig as an Experimental Model for Clinical Craniofacial Research. Laboratory Animals, 46, 269-279. https://doi.org/10.1258/la.2012.012062

[22] Ruiz-Ederra, J., Garcia, M., Hernandez, M., Urcola, H., Hernandez-Barbachano, E., Araiz, J., et al. (2005) The Pig Eye as a Novel Model of Glaucoma. Experimental Eye Research, 81, 561-569. https://doi.org/10.1016/j.exer.2005.03.014

[23] Kivell, T.L., Doyle, S.K., Madden, R.H., Mitchell, T.L. and Sims, E.L. (2009) An Interactive Method for Teaching Anatomy of the Human Eye for Medical Students in Ophthalmology Clinical Rotations. Anatomical Sciences Education, 2, 173-178.

[24] Wang, Q., Wang, J. and Wang, T. (2016) Pigs Can Be Used as a Large Animal Model for Autologous Fat Grafting. Ophthalmic Plastic and Reconstructive Surgery, 32, 73-74. https://doi.org/10.1097/IOP.0000000000000547

[25] Suner, S., Simmons, W. and Savitt, D.L. (2000) A Porcine Model for Instruction of Lateral Canthotomy. Academic Emergency Medicine, 7, 837-838. https://doi.org/10.1111/j.1553-2712.2000.tb02283.x

[26] Aurich, L.A., Silva, L.F., Monteiro, F.M., Ottoni, A.N., Jung, G.S. and Ramina, R. (2014) Microsurgical Training Model with Nonliving Swine Head. Alternative for Neurosurgical Education. Acta Cirurgica Brasileira, 29, 405-409. https://doi.org/10.1590/S0102-86502014000600010

[27] Shentu, X., Tang, X., Ye, P. and Yao, K. (2009) Combined Microwave Energy and Fixative Agent for Cataract Induction in Pig Eyes. Journal of Cataract \& Refractive Surgery, 35, 1150-1155. https://doi.org/10.1016/j.jcrs.2009.02.045

[28] Ramakrishnan, S., Baskaran, P., Fazal, R., Sulaiman, S.M., Krishnan, T. and Venkatesh, R. (2016) Spring-Action Apparatus for Fixation of Eyeball (SAFE): A Novel, Cost-Effective yet Simple Device for Ophthalmic Wet-Lab Training. British Journal of Ophthalmology, 100, 1317-1321.

https://doi.org/10.1136/bjophthalmol-2015-308330

[29] Mohammadi, S.F., Mazouri, A., Rahman, A.N., Jabbarvand, M. and Peyman, G.A. (2011) Globe-Fixation System for Animal Eye Practice. Journal of Cataract \& Refractive Surgery, 37, 4-7. https://doi.org/10.1016/j.jcrs.2010.10.026 
[30] Otto, C.S. (2005) Device for Simulating Anterior Segment Surgery. Journal of Cataract \& Refractive Surgery, 31, 1287-1289. https://doi.org/10.1016/j.jcrs.2004.11.036

[31] Bertschinger, D.R., Beknazar, E., Simonutti, M., Safran, A.B., Sahel, J.A., Rosolen, S.G., et al. (2008) A Review of in Vivo Animal Studies in Retinal Prosthesis Research. Graefe's Archive for Clinical and Experimental Ophthalmology, 246, 1505-1517. https://doi.org/10.1007/s00417-008-0891-7

[32] Barbe, C., Raymond-Letron, I., Mias, G.P., Charron, J. and Goulle, F. (2017) Marsupialization of a Cyst of the Nictitating Membrane in Three Dogs. Veterinary Ophthalmology, 20, 181-188. https://doi.org/10.1111/vop.12382

[33] Dees, D.D., Schobert, C.S., Dubielzig, R.R. and Stein, T.J. (2016) Third Eyelid Gland Neoplasms of Dogs and Cats: A Retrospective Histopathologic Study of 145 Cases. Veterinary Ophthalmology, 19, 138-143. https://doi.org/10.1111/vop.12273

[34] Gornik, K.R., Pirie, C.G. and Beamer, G.L. (2015) Unilateral Choristoma of the Nictitating Membrane in a Horse. Journal of the American Veterinary Medical Association, 246, 231-235. https://doi.org/10.2460/javma.246.2.231

[35] Kehoe, E.J., Ludvig, E.A. and Sutton, R.S. (2013) Timing and Cue Competition in Conditioning of the Nictitating Membrane Response of the Rabbit (Oryctolagus cuniculus). Learning \& Memory, 20, 97-102. https://doi.org/10.1101/lm.028183.112

[36] Kyllar, M., Stembirek, J., Danek, Z., Hodan, R., Stransky, J., Machon, V., et al. (2016) A Porcine Model: Surgical Anatomy of the Orbit for Maxillofacial Surgery. Laboratory Animals, 50, 125-136. https://doi.org/10.1177/0023677215577923

[37] Sanchez, I., Martin, R., Ussa, F. and Fernandez-Bueno, I. (2011) The Parameters of the Porcine Eyeball. Graefe's Archive for Clinical and Experimental Ophthalmology, 249, 475-482. https://doi.org/10.1007/s00417-011-1617-9 